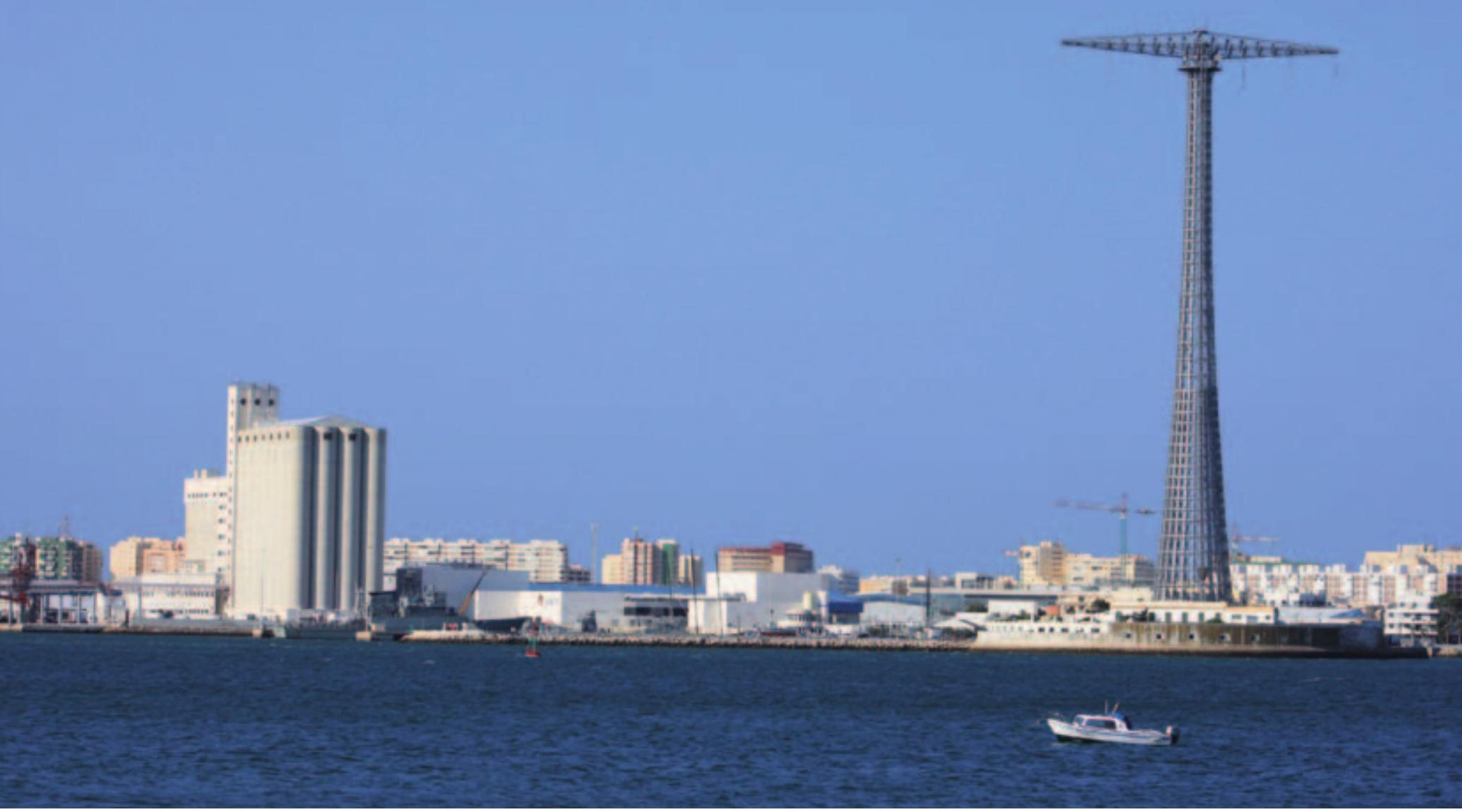

Bahía de Cádiz con la harinera Villafranquina y la torre del tendido eléctrico de Puntales (Alberto Toscano, 1955) en el horizonte. Foto: Fondo Gráfico IAPH (Marta Santofimia) 


\section{El patrimonio industrial en la Bahía de Cádiz: un itinerario cultural}

Marta Santofimia Albiñana,

arquitecto colaborador del Centro de Documentación y Estudios del IAPH
El legado de la industrialización es fruto de la necesidad de dar respuesta a los nuevos sistemas productivos surgidos a principios del siglo XIX que pretendian superar el marco disperso de la elaboración artesanal para iniciar un proceso de mecanización significativo. La desamortización del suelo, la mecanización de la industria y el despegue de las construcciones mecánicas serán instrumentos fundamentales en la renovación económica acontecida en España en el primer tercio del siglo XIX. Un recorrido por cinco de los elementos del patrimonio industrial de la Bahía de Cádiz ofrece una lectura cronológica desde los primeros cambios modernizadores de las Reales Fábricas, hasta los últimos ejemplos situados en el cambio del modelo mecanizado al de procesos automatizados.

La razón de ser de este itinerario responde a la propia lógica geográfica de las industrias que buscan bien la explotación y transformación de los recursos inherentes al territorio, como es en nuestro caso los recursos marinos (salinas-conservas, molinos de mareas y astilleros); bien la elaboración de las materias primas de diversos orígenes que, a través de medios de transporte y comunicación como el ferrocarril y los puertos, tengan entrada en ese territorio, como es el caso de la producción del tabaco procedente de las colonias que tenía entrada por los puertos andaluces de Cádiz, Málaga y Sevilla, o la molienda del cereal para la producción de harinas.

Recorriendo el saco interior de la Bahía de Cádiz en el sentido inverso al movimiento de las agujas del reloj, dividiremos este itinerario en cuatro etapas. La primera de ellas, la representada por la Fábrica Nacional de Tabacos y los almacenes de Tabacalera, corresponde a la primera revolución industrial (1830-1888), caracterizada por la confluencia de modernización tecnológica y tradición artesanal. La segunda, incluida a modo de referencia, está formada por los numerosos ejemplos de las actividades preindustriales desarrolladas en la Bahía vinculadas a la explotación de los recursos presentes en el territorio. El dique de Matagorda sirve de ejemplo a la caracterización de la gran industria o segunda revolución industrial (1888-1936), desarrollada por la aparición de la electricidad, los vehículos de motor de combustión y la industria química, y constituye la tercera etapa de nuestro recorrido. Por úl- timo, la cuarta etapa viene de la mano de las torres de electricidad de la Bahía y la harinera Villafranquina como representantes de la tercera revolución industrial (1939-1990).

Comenzaremos nuestro itinerario junto al puerto de la ciudad de Cádiz, en la plaza que toma el nombre de la extinta Puerta de Sevilla, a pocos metros de la estación del ferrocarril (1861). En este lugar estratégico para el comercio encontramos el edificio de la Fábrica Nacional de Tabacos de Cádiz (Federico Gil de los Reyes, 1883) que se presenta como uno de los mejores exponentes de la historia contemporánea del tabaco en Andalucia junto con las Reales Fábricas de Tabaco de Sevilla (1728) y Málaga (1928).

Esta industria, pionera en la manufactura del tabaco en Andalucía y cuyos precedentes recibieron la distinción de Real Fábrica (1741), ocupó las dependencias de la antigua alhóndiga de la ciudad (1829) y las transformó, años más tarde, en una nueva instalación. Esta fábrica reunió en un mismo espacio el proceso productivo completo caracterizado por el trabajo colectivo en cadena, abandonando asi el anterior sistema gremial de producción. Su tipología arquitectónica es la de palacio urbano de planta baja, principal y segunda, con cubierta de azotea o teja plana vidriada, articulado en torno a un patio principal. En su interior, la actividad productiva se organiza a partir de hermosas galerías de estructura de fundición que sirven de paso a los diferentes servicios del establecimiento. Hacia el exterior, el uso del ladrillo cara vista como material para el cerramiento evidencia la vinculación del edificio a la industria, y un gesto de inspiración nostálgica en la arquitectura mudéjar se presenta en la labra de las cornisas y de los recercados de los huecos formados por arcos de medio punto. Actualmente, el almacén anexo a la fábrica (1897) se ha convertido en la imagen principal del Palacio de Congresos de la ciudad.

La lógica de implantación de las industrias también se aplicó a su localización en las ciudades, como es el caso de los depósitos de tabaco con los que continuaremos nuestro recorrido. Colmatados los espacios intramuros, las industrias buscaron su sitio extramuros aprovechándose de una mejor accesibilidad a los sistemas de distribución. 

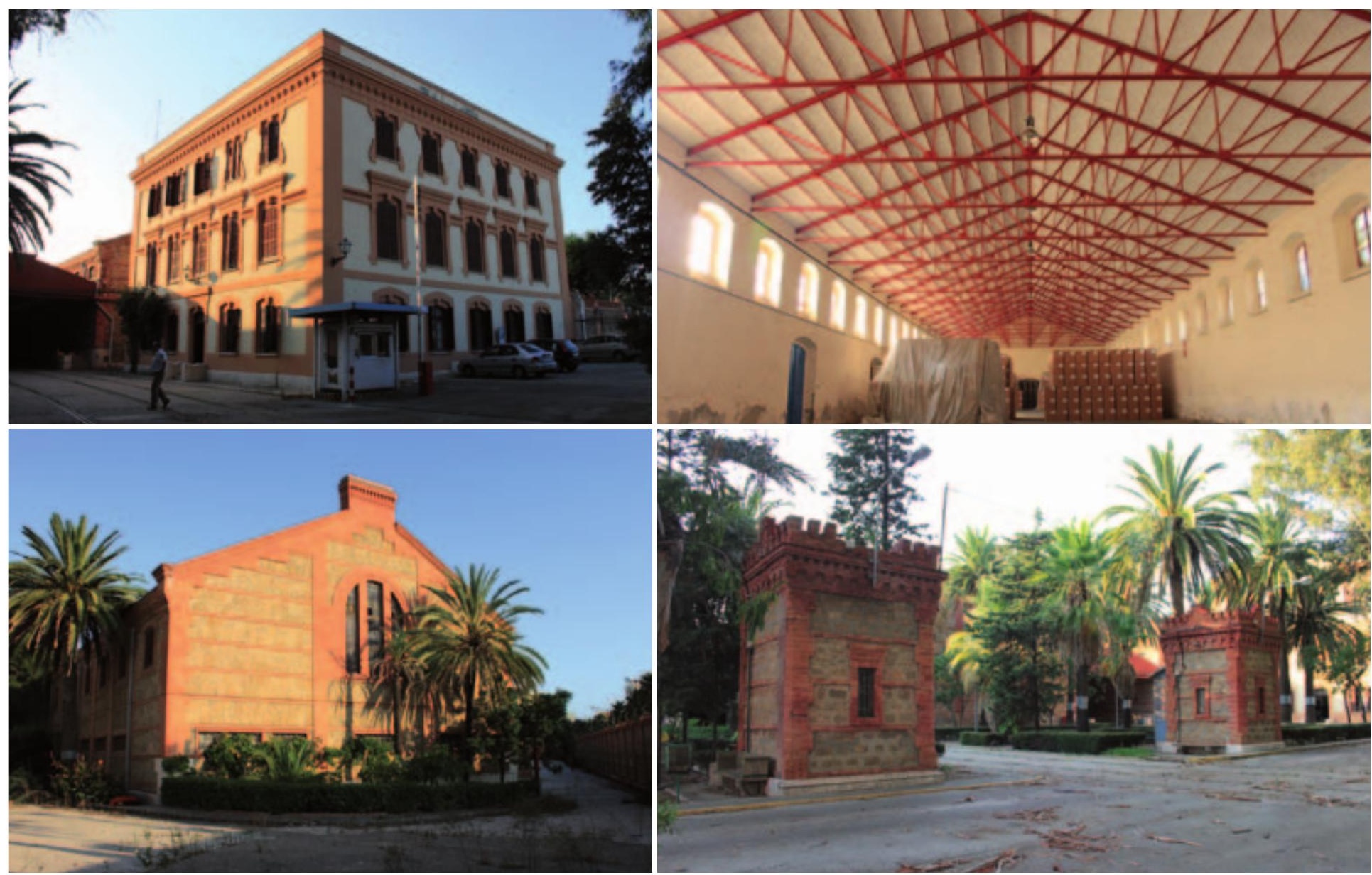

Edificios de viviendas de los depósitos de Tabacalera Depósitos de Tabacalera

Fotos: Fondo Gráfico IAPH (Marta Santofimia)

Edificios de distribución de la Tabacalera

Garitas de control de acceso de los trenes a los andenes de la Tabacalera Fotos: Fondo Gráfico IAPH (Plácido González)

En un solar situado en las cercanías de la zona franca del puerto de Cádiz, con la que se conectaba originalmente a través del ferrocarril, encontramos los depósitos de Tabacalera (1910), producto del incremento del consumo derivado del aumento de la población y de la extensión del hábito al medio rural. A finales del siglo XIX, la presión de la demanda exigió un modelo de gestión diferente al monopolio estatal que identificaba a la Fábrica Nacional de Tabacos que incluyese la decidida mecanización de los sistemas productivos y el incremento de la productividad de la mano de obra. Producto de este contexto son los nuevos depósitos de la Tabacalera.

El complejo se compone de un área residencial y una de almacenaje y distribución. El área residencial se concentra en dos edificios de planta cuadrada y tres de altura organizados alrededor de un patio, al que se abre una caja de escaleras, que sirve a dos viviendas por planta. La imagen exterior es la propia de la arquitectura ecléctica del momento. El otro área se compone de cuatro naves paralelas y una perpendicular a ellas dedicadas al almacenaje, entre las cuales se sitúan los andenes de ferrocarril para la descarga del material procedente del puerto. A continuación, anexa a la nave transversal de almacenaje, se desarrolla la zona de distribución, formada por dos naves en $L$ dedicadas a la carga de mercancias para su reparto a través de camiones. Hacia el exterior el cerramiento de las naves mezcla el ladrillo visto de color rojizo y la piedra ostionera del lugar. El conjunto se completa con un frondoso jardín de trazado regular situado frente al acceso principal, dos garitas de control de acceso de los trenes a los andenes y un espacio ajardinado situado entre las vías que conectaban con la zona franca del puerto de Cádiz.

Industrias como la del tabaco, pertenecientes a los sectores industriales no tradicionales, precursoras del proceso de inversión, expansión comercial, crecimiento y aporte científico a partir del empleo de nuevas fuentes de energía, configuraron el marco económico de comienzos del siglo XX en Andalucía.

Sin embargo, España fue hasta el primer tercio del siglo XIX un país esencialmente agrario cuyo legado lo encontramos en multitud de ejemplos de industrias alimentarias básicas como salinas, molinos de marea, almadrabas, bodegas y canteras, ejemplos de una preindustrialización que se explica por sí sola en esta segunda etapa del itinerario que nos conduce hacia la zona sur del saco interior de la Bahía de Cádiz.

Las salinas tradicionales son el resultado de la antropización durante siglos de las marismas para la producción de sal. Este valioso patrimonio, distribuido en la Bahía en tres áreas principales (las marismas de San Fernando, Puerto Real y Chiclana; las marismas 
La tercera zona del conjunto es la que tiene como núcleo la capilla y los dos edificios anexos, de escuela y asilo, en torno al jardin que preside la escultura del marqués de Comillas, fundador de la compañia Trasatlántica. Se trata del recinto en el que se concentró la mayor carga simbólica, actuando como centro de la primitiva colonia industrial (1880), hoy desaparecida. La capilla, de planta de cruz griega, es un ejemplo destacado de la fantasía historicista de la arquitectura de finales del siglo XIX donde la máxima de la arquitectura del fin del siglo XIX por la integración de las artes decorativas se muestra cargada de expresividad. Construida en piedra hasta el arranque de la cúpula, un curioso juego de materiales en la construcción de la cubierta permitió burlar las restricciones por las que se prohibian edificaciones permanentes de más de una planta de altura en la Bahía de Cádiz. Otras construcciones como el edificio de los antiguos comedores (1894), las oficinas, actual archivo de la empresa y la torre mirador (A. Lopera y J. M. Hernández de León) completan el conjunto.

A ambos lados de la embocadura de la bahía interior de Cádiz, en Puerto Real y Cádiz respectivamente, encontramos las ensoñadoras torres del tendido eléctrico de Matagorda y Puntales (Alberto Toscano, 1955), un alarde de construcción moderna que permite el tendido de cables de conducción eléctrica desde la central térmica de Cádiz hasta la red general.

Diseñadas para salvar una distancia de 1639 metros manteniendo un gálibo mínimo de 50 metros para permitir el paso ininterrumpido de barcos en la Bahía se presentan como un mástil hueco de 160 metros de altura, de sección circular y forma troncocónica cuyos perfiles dibujan una suave curvatura desde la cúspide, de 6 metros de diámetro, hasta la base, de 20,70 metros. El mástil se corona con una viga travesaña de sección romboidal variable y 70 metros de longitud total, que sostiene los seis cables de alta tensión que corren de torre a torre. En el interior de la estructura, una escalera helicoidal recorre el mástil permitiendo ascender al travesaño superior.

El último elemento de nuestro recorrido es la harinera Villafranquina (1996) dedicada a la producción de harinas y a la preparación de trigo para la exportación. Situada en la zona franca del puerto de Cádiz, junto a la torre del tendido eléctrico de Puntales, se ha convertido, con su rotundo volumen, en uno de los hitos visuales más reconocibles del perfil de la ciudad hacia la Bahía.

El edificio principal de la harinera se sitúa en el extremo norte de las instalaciones. Con una longitud aproximada de 150 metros y una altura de diez plantas, su estructura y organización se resuelven según los dictados de las necesidades de la producción. Su volumen queda determinado por las baterías de silos que se muestran vistos hacia el exterior. El bloque de producción del edificio, de diez plantas de altura, cuenta con una batería de $4 \times 8$ silos en su extremo sur, y de $4 \times 4$ silos en su extremo norte. Entre ambas baterias, se desarrolla la fábrica. Los silos de almacenamiento, de mayor altura y diámetro, se localizan, formando una batería de $4 \times 7$ silos, en el extremo norte del bloque de producción. Un núcleo

\section{Un recorrido por cinco elementos del patrimonio industrial de la Bahía de Cádiz que ofrece una lectura desde los primeros cambios modernizadores hasta los últimos ejemplos del modelo mecanizado}

de comunicaciones verticales de mayor altura conecta el bloque de producción y los silos.

A través del recorrido marcado, se narra uno de los numerosos relatos del desarrollo del sector agroalimentario que, junto a otros sectores como el minero, el textil o el metalúrgico, acompañó a la modernización territorial y social andaluza en el siglo XIX. Un proceso que, tal y como hemos señalado, modificó el paisaje urbano de las ciudades y su entorno a través de elementos que se deben conocer, preservar y establecer como señas de identidad común.

Se busca así, con esta ruta por cinco elementos del patrimonio industrial de Cádiz, añadir una nueva capa de conocimiento a la propuesta "Tres itinerarios culturales para el Parque Natural Bahía de Cádiz: arquitectura preindustrial, defensiva y del agua", publicada por José Ramón Barros en el PH Boletín del IAPH 35 (2001) con la intención de contribuir, a través de la superposición de todas ellas, a la puesta en valor del patrimonio cultural de la Bahía de Cádiz.

\section{Bibliografía}

BELTRÁN, N. (2012) Las torres del tendido eléctrico de Matagorda y Puntales, Cádiz. Fichas de documentación. En Registro Andaluz de Arquitectura Contemporánea [en línea] Sevilla: IAPH, $2012<$ http://www.iaph.es/patrimonioinmueble-andalucia/resumen.do?id=i20651>; <http://www.iaph.es/patrimonioinmueble-andalucia/resumen.do?id=i413> [Consulta: 17/05/2012] GONZÁLEZ MARTíNEZ, P. (2012) Harinera Villafranquina, Cádiz. Ficha de documentación. En Registro Andaluz de Arquitectura Contemporánea [en línea] Sevilla: IAPH, 2012 <http://www.iaph.es/patrimonio-inmueble-andalucia/ resumen.do?id=i21058> [Consulta: 17/05/2012]

GONZÁLEZ MARTíNEZ, P. (2012) El dique de Matagorda, Cádiz. icha de documentación. En Registro Andaluz de Arquitectura Contemporánea [en linea] Sevilla: IAPH, 2012 <http://www.iaph.es/patrimonio-inmueble-andalucia/ resumen.do?id=i17028> [Consulta: 17/05/2012]

JIMÉNEZ MATA, J. (1995) Guía de arquitectura de Cádiz. Sevilla: Consejeria de Obras Públicas y Transportes, 1995

NADAL, J. (1997) El fracaso de la Revolución Industrial en España: 1814-1913. Barcelona: Ariel, 1997

SOBRINO SIMAL, J. (1989) Arquitectura industrial en España (1830-1990). Madrid: Banco de Crédito Industrial, 1989

\section{Recursos digitales de interés}

Base de datos del patrimonio inmueble de Andalucia www.iaph.es/patrimonio-inmueble-andalucia

Base de datos del Registro Andaluz de Arquitectura Contemporánea www.iaph.es/arquitectura-contemporanea-andalucia

Canal Patrimonio Contemporáneo

www.iaph.es/patrimoniocontemporaneo

Video de presentación del patrimonio contemporáneo: El movimiento moderno en la arquitectura andaluza

www.youtube.com/watch?v=qG52-DQmhi8 